\title{
Multiple Intraosseous Lipomatosis - A Case Report and a Review of the Literature
}

\author{
DIETMAR DAMMERER ${ }^{1}$, JOHANNES NEUGEBAUER $^{1}$, DAVID PUTZER $^{2}$ and BENJAMIN HENNINGER ${ }^{3}$ \\ ${ }^{1}$ Department of Orthopaedics and Traumatology, Medical University of Innsbruck, Innsbruck, Austria; \\ ${ }^{2}$ Department of Orthopaedics - Experimental Orthopaedics, Medical University of Innsbruck, Innsbruck, Austria; \\ ${ }^{3}$ Department of Radiology, Medical University of Innsbruck, Innsbruck, Austria
}

\begin{abstract}
Background: Intraosseous lipomatosis is a rare and uncommon entity with only a few cases reported in the literature. Case Report: We report a severe case where posttraumatic radiographs showed multiple cystic osseous lesions and a pathological fracture. The findings were expanded with whole-body magnetic resonance imaging (MRI), which showed multiple osseous lesions with typical MRI characteristics of intraosseous lipomas. Conclusion: Our case, together with very few other cases described in the literature, emphasizes that multiple intraosseous lipomatosis is an important differential diagnosis for multiple radiolucent lesions on plain radiographs. Multiple intraosseous lipomatosis can lead to pathological fractures and severe impairment of life quality. The presence of well-defined, osteolytic lesions in the bone calls for an MRI or computed tomography scan.
\end{abstract}

Multiple intraosseous lipomatosis (MIL) is a highly uncommon and rare bone condition and only few cases have been previously published (Table I) (1). According to the current literature, MIL is an idiopathic entity of unexplained etiology and unknown pathogenesis (1). Intraosseous lipomas are often found accidentally or in combination with (pathological) fractures (2). The dia- and meta-physis of long tubular bones and the calcaneus are considered the most common sites of manifestation (3). Over one-third are localized in the proximal femur and the intertrochanteric region. Prevalence is the same for men and women (1).

This article is freely accessible online.

Correspondence to: Johannes Neugebauer, MD, Department of Orthopaedics and Traumatology, Medical University of Innsbruck, Anichstrasse 35, 6020 Innsbruck, Austria. Tel: +43 51250422691, Fax: +43 51250422693, e-mail: johannes.neugebauer@tirolkliniken.at

Key Words: Multiple intraosseous lipomatosis, bone cysts, radiolucent lesions, bone tumors.
Histologically, osseous lipomas consist of mature fatty tissue and are benign tumors. Whether osseous lipomas occasionally represent healing stages of other lesions (nonossifying bone fibromas, chondroblastomas) is the subject of ongoing discussion. Following degenerative transformation lipomas can correspond to radio- and histo-logically solitary bone cysts.

Radiologically, intraosseous lipomas show a wide range of differential diagnoses in plain radiographs - a welldefined margin gives rise to the diagnosis of a benignappearing osteolytic lesion. Central calcification can occur. With magnetic resonance imaging (MRI) the typical signal characteristics narrow down the differential diagnosis to a fat-containing osseous lesion: hyperintense on T1-weighted images with signal cancellation in fat-saturated sequences. These imaging features show a variance concerning different degrees of involution and necrosis. Milgram et al. proposed three categories ranging from the typical homogeneous fatty tissue to calcification or cystic changes (4-6). Furthermore, computed tomography (CT) can also establish the diagnosis by measuring attenuation.

\section{Case Report}

We present the case of a 31-year-old Italian Caucasian male patient, with a pathological compression fracture of the right tibial plateau. Anamnestically, there was no history of trauma that would have led to the above-mentioned fracture. The patient was $176 \mathrm{~cm}$ tall, weighed $70 \mathrm{~kg}$ (BMI 22.6) and was active in sports. According to his family history, his mother suffered from Marfan syndrome. The patient himself was never diagnosed with this syndrome, and the family has no further history of musculoskeletal disease.

His medical and surgical history was significant for a bilateral comminuted talus fracture and a prior pathological fracture of the right scaphoid (treated with a blastacast). The patient's medical history began in 2004 at the age of 14 years. In a skiing accident in a jump on a ski slope, he suffered a 
Table I. Compilation of literature.

\begin{tabular}{|c|c|c|c|c|}
\hline Author/Year & Study & Subject & Findings & LoE \\
\hline $\begin{array}{l}\text { Palczewski et al., } \\
2011 \text { (16) }\end{array}$ & Case report & Radiology & $\begin{array}{l}\text { - Lesions were diagnosed incidentally } \\
\text { - Adipose tissue in malignant tumors is extremely rare } \\
\text { - A sclerotic rim surrounding lesions was identified in every case }\end{array}$ & 5 \\
\hline $\begin{array}{l}\text { Rehani and Wissman, } \\
2009 \text { (1) }\end{array}$ & Case report & Radiology & $\begin{array}{l}\text { - Additional studies include complete blood count with normal results } \\
\text { - Intraosseous lipomas are mostly solitary lesions, multiple lesions are unusual } \\
\text { Multiple intraosseous lipomas have been reported in some patients with } \\
\text { hyperlipoproteinemia, macrodystrophia lipomatosa and as a congenital variant } \\
\text { following autosomal pattern of inheritance, although their etiology is unknown }\end{array}$ & 5 \\
\hline $\begin{array}{l}\text { Campbell et al., } \\
2003 \text { (7) }\end{array}$ & Case report & Radiology & $\begin{array}{l}\text { - Lesions are seen as an end result of a process of involution of bone lesions } \\
\text { - Isolated diaphyseal or epiphyseal involvement is unusual } \\
\text { - Marginal sclerosis was manifested by a rim of low-signal all-pulse sequences. } \\
\text { - CT shows all lesions have low attenuation equivalent to fat density, identification } \\
\text { of fat density on CT is usually considered diagnostic of an intraosseous lipoma } \\
\text { - Most lipomas can be managed conservatively } \\
\text { - Surgical treatment usually includes curettage and packing with bone chips }\end{array}$ & 5 \\
\hline $\begin{array}{l}\text { Szendroi et al., } \\
1991 \text { (17) }\end{array}$ & Case report & $\begin{array}{l}\text { Orthopaedic } \\
\text { surgery }\end{array}$ & $\begin{array}{l}\text { - Patient with slowly progressive systemic intraosseous lipomatosis } \\
\text { - Diagnosis caused by a pathological fracture after inadequate trauma } \\
\text { - Intraosseous lipomatosis is a disease of unknown origin } \\
\text { - Not associated with abnormal lipid metabolism } \\
\text { - Management of intraosseous lipomatosis is an unsolved problem } \\
\text { - Treatment of pathological fractures } \\
\text { - Curettage and graft lesions appear to provide such a hazard }\end{array}$ & 5 \\
\hline $\begin{array}{l}\text { Murphey et al., } \\
2004 \text { (18) }\end{array}$ & Review & Radiology & $\begin{array}{l}\text { Benign lipomatous lesions affecting bone include intraosseous lipoma, } \\
\text { parosteal lipoma, and liposclerosing myxofibrous tumor (LSMFT). } \\
\text { - Although generally considered rare, intraosseous lipoma, in our experience, } \\
\text { occurs with much greater frequency than the widely cited prevalence of less } \\
\text { than one per } 1000 \text { cases of primary bone tumor } \\
\text { - Multiple intraosseous lipomas affecting more than } 10 \text { bones in a single } \\
\text { patient (intraosseous lipomatosis) have also been reported, both with and } \\
\text { without associated hyperlipoproteinemia } \\
\text { - Histologic evidence of ischemia in intraosseous lipomas has led to the speculation } \\
\text { that slow enlargement of a lipoma in the enclosed space of the medullary canal } \\
\text { may lead to increased intramedullary pressure } \\
\text { - Increased intramedullary pressure may then compromise blood flow, } \\
\text { particularly in venous structures } \\
\text { - Central or ring-like calcification in a lucent lesion involving the body of the } \\
\text { calcaneus is pathognomonic of an intraosseous lipoma and allows it to be } \\
\text { distinguished from a unicameral bone cyst }\end{array}$ & 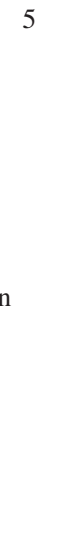 \\
\hline $\begin{array}{l}\text { Kang et al., } \\
2018 \text { (19) }\end{array}$ & $\begin{array}{l}\text { Retrospective } \\
\text { Cohort Study }\end{array}$ & $\begin{array}{l}\text { Clinical } \\
\text { orthopedic } \\
\text { surgery }\end{array}$ & $\begin{array}{l}\text { - No complaints of functional limitation } \\
\text { - No correlation between the degree of degeneration and clinical symptoms } \\
\text { - No local recurrence or malignant change during follow-up. } \\
\text { The pathogenesis of intramedullary lipoma has not been clarified. } \\
\text { Several hypotheses have been proposed including secondary } \\
\text { bone reaction after trauma, healing reaction of osteonecrosis, } \\
\text { and primary benign tumors } \\
\text { - Radiological follow-up with conservative treatment is recommended, except } \\
\text { for rare cases with risk of pathological fractures or malignant transformation }\end{array}$ & 5 \\
\hline
\end{tabular}

LoE: Levels of evidence; CT: Computed tomography.

bilateral ankle trauma including a bilateral comminuted talus fracture, a left-sided calcaneus comminuted fracture, as well as multiple stress fractures described with bleeding into the talus, calcaneus and cuboid on both sides. Extensive reconstructive surgery was performed. For the first time, "less mineralized" bone areas were conspicuous, but were evaluated post-trauma. This was followed by a long phase of rehabilitation. Demotivated by the severe trauma and the associated pain, the patient reduced his sports activity to a minimum. After a bicycle accident at the age of 28 years, a CT scan was made on suspicion of a scaphoid fracture. Again, osseous irregularities were found. 


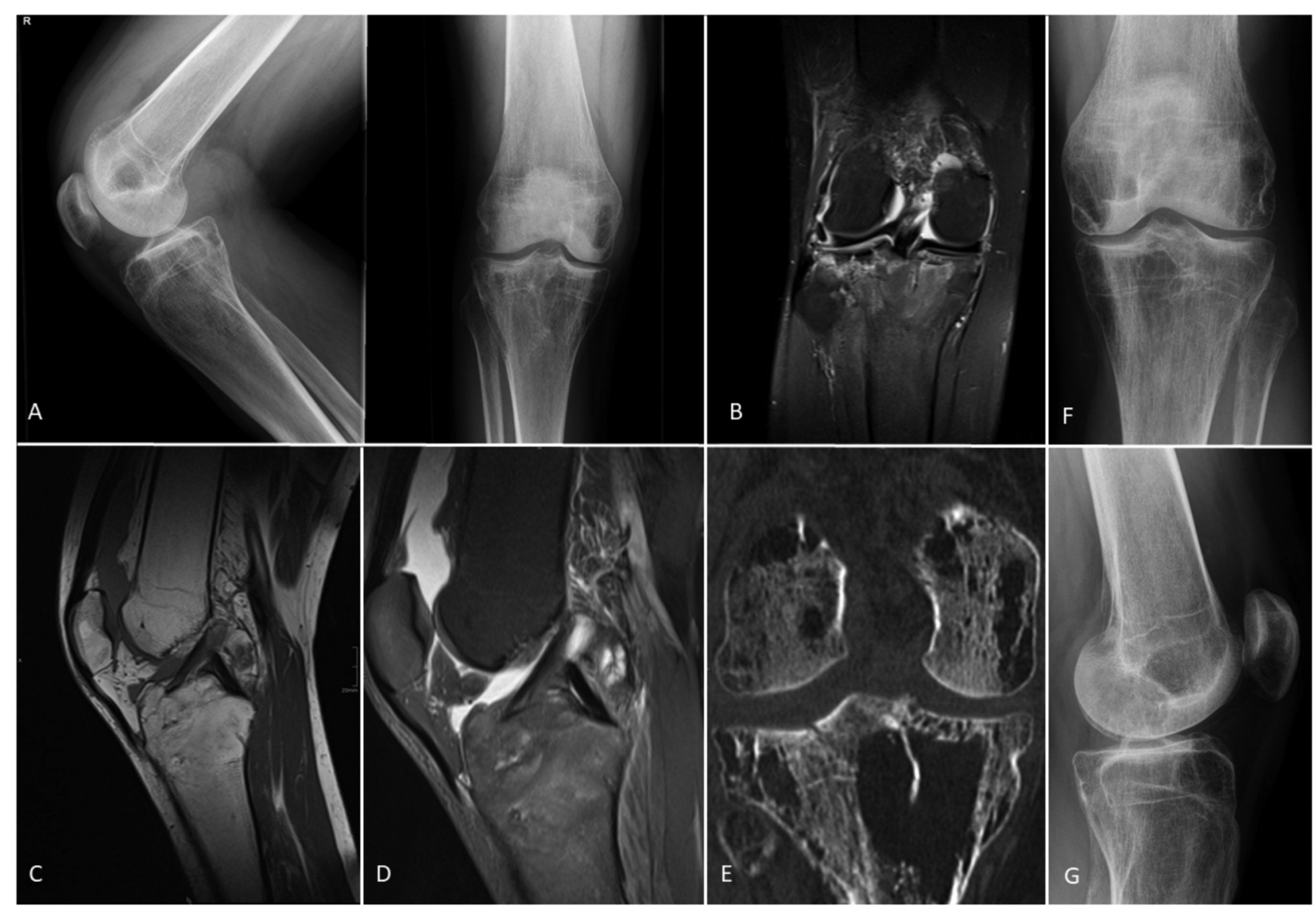

Figure 1. The initial plain radiograph of the right knee (A) shows osteolytic lesions with a well-defined sclerotic margin in the epi-and metaphysis of the distal femur and proximal tibia. MRI confirms these findings as fat-containing lesions with a hypo-to slightly hyperintense signal on intermediate-weighted images with fat saturation $(B+D)$ and a hyperintense signal on T1-weighted images $(C)$. The fracture of the lateral tibia plateau $(B)$ was confirmed by $C T(E)$, also showing lesions with low attenuation, typical of fat. A plain radiograph of the opposite knee reveals similar lesions of the bone $(F+G)$.

Retrospectively, the trauma that may have led to the fractures had not been considered severe enough in a young man with no tumor history. The fractures of the ankle and the suspected fracture of the scaphoid were treated in a peripheral hospital.

In 2020, while taking a high-ropes course, the abovementioned tibia plateau fracture occurred with a low-energy injury. A native $x$ ray image of the opposite side of the knee joint was taken (summary of all relevant images in Figure 1). Initial native radiographs showed well-defined, radiolucent lesions forming osteolytic-appearing lesions in the proximal shin- and the distal thighbone. In the course of radiological diagnosis of a tibial head compression fracture of the right side, multiple "aneurysmatic bone cysts" were detected. The findings were expanded in a whole-body magnetic resonance imaging (MRI) (Figure 2).

The MRI examination showed multiple intraosseous lipomatosis. The involvement showed its maximum extension in the long tubular bones, epi- and metaphyseal: both knee joints were affected, with an additional tibial plateau fracture on the right and a tibial compression fracture on the left. Additionally, both humerus heads, both ankle joints, both greater trochanter and the iliosacral joint on both sides were affected. Following a meeting of our interdisciplinary bone and soft tissue sarcoma board, we decided to undertake a surgical procedure including complete blood count, liver, renal and thyroid function tests, serum lipid panel, serum electrophoresis and genetic diagnosis. All results of these tests were normal.

\section{Discussion}

According to the literature (Table I), intraosseous lipomas are very rare entities and were first described in $1880(7,8)$. Although the incidence of intraosseous lipoma is thought to be less than $0.1 \%$ of all primary bone tumors, its true incidence 


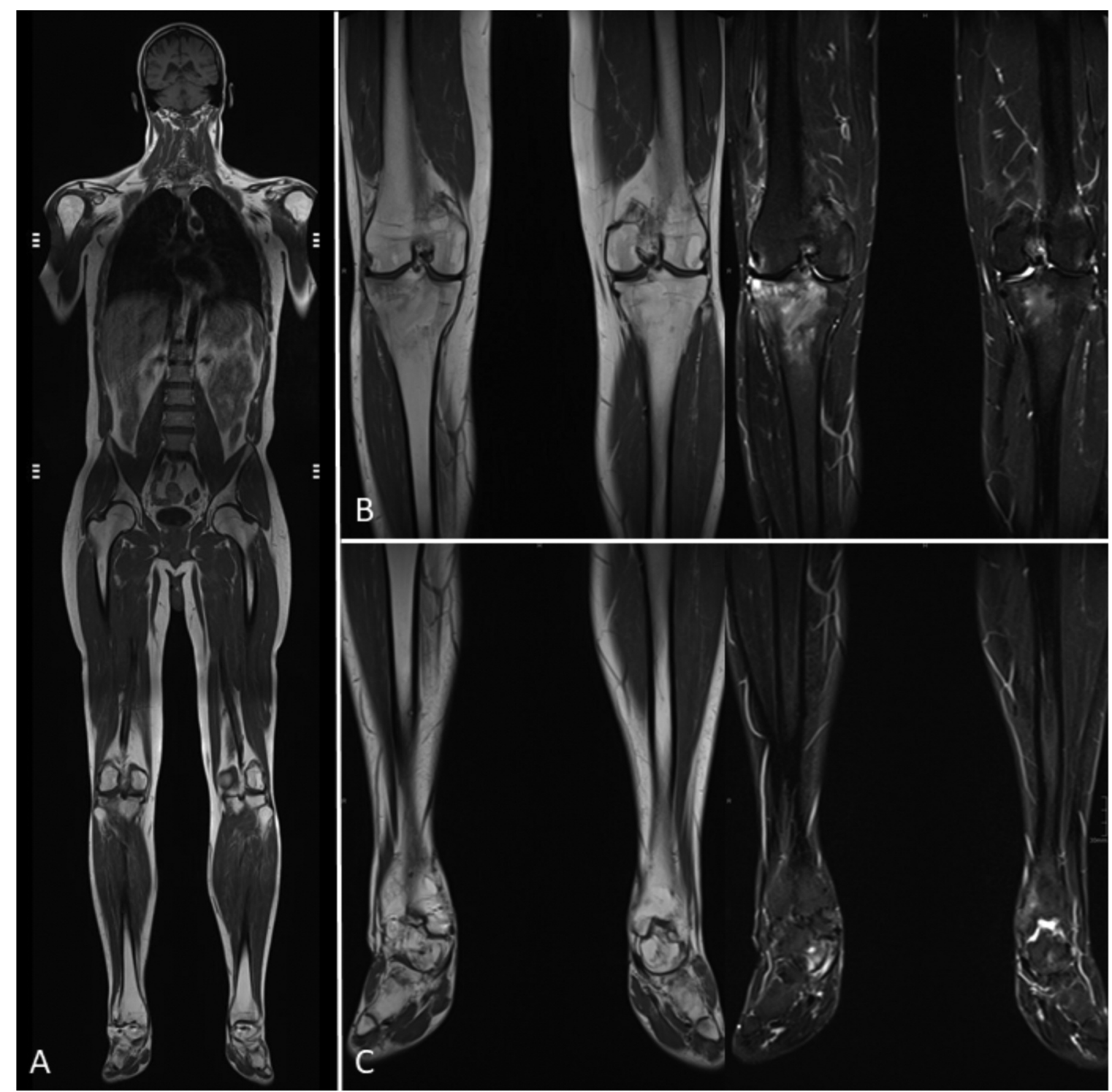

Figure 2. Whole-body MRI (A) scan confirms the suspected diagnosis of multiple intraosseous lipomatosis. Multiple fat-containing lesions of the bone were found in both knee and ankle joints $(B+C)$ with typical signal characteristics.

may be much higher (9). This is because many patients have no symptoms, and are thus unlikely to ever consult an orthopedic clinic (9). Although their etiology is still unknown, multiple intraosseous lipomas have been reported in patients with hyperlipoproteinemia, macrodystrophia lipomatosa and as a congenital variant following an autosomal pattern of inheritance (3, 9-11). Clinically, intraosseous lipomas may cause symptoms like pain when present in weight-bearing bones $(4,12-14)$, but a study by Goto et al. found that only two of 13 affected patients were clinically symptomatic (15).

The available literature shows that intraosseous lipomas are almost always solitary lesions, with multiple bony involvements being highly unusual and rare (1). They are mostly accidental radiological findings or are recognized as a result of pathological fractures $(1,3,7)$. Because the entire bone marrow is rich in fat, the formation can affect practically all parts of a bone $(1,3,7)$. However, the diaphyses of long tubular bones and the lower extremities are more frequently affected $(1,3,7)$. Critical differential diagnoses (the simple bone cysts, bone infarcts, fibrous dysplasia, aneurysmal bone cysts, chondroid and myxoid tumors) can be excluded with the help of a multidisciplinary and interdisciplinary bone and soft tissue sarcoma board (1, $3,7)$. When in doubt, a biopsy should be taken (7). 
In summary, with knowledge of this rare entity, clinicians have a greater tendency to initiate proper diagnostic procedures to diminish the risk of future pathological fractures and to consider various treatment options. The rarity of this exceptional condition is reflected in the literature, where only a small number of studies have been published $(1,3,7)$. To the best of our knowledge, no studies report on the frequency, appearance or the diagnosis and treatment strategies for this entity. This means that diagnosis and treatment are influenced more by the experience of the treating doctor than by evidence-based medicine. Protecting the patient from potential fractures is probably the most important therapeutic consideration. Extensive and targeted diagnostics are essential. Only when the extent of the disease has been revealed, as in the present case, can targeted treatment strategies be considered. While intraosseous lipomatosis is usually described in the literature as a singular phenomenon within a bone, the present case report shows the even more uncommon picture of "whole-body manifestation". In our patient, both the upper and the lower limbs were seen to be affected and there was no above-mentioned coexisting condition that could have predisposed to this condition.

As mentioned in the literature, we state as limitation that all decisions were influenced more by the clinical experience of our interdisciplinary musculoskeletal tumor board team in a tertiary sarcoma center than by evidence-based knowledge. We therefore chose the most evident treatment option including curettage with or without bone grafting, or with a bone graft substitute (9).

We conclude that in order to support clinicians with a multicenter study or expert opinions, diagnostic algorithms should be established. In this case, too, a more precise diagnosis could have prevented the fracture of the tibial head of the patient, which is post-traumatic and promotes the development of post-traumatic gonarthrosis. Additionally, physicians should be aware of and consider this rare condition, which may help in reaching the right diagnosis and case management. Even an entity as rare as multiple intraosseous lipomatosis can lead to pathological fractures and severe impairment of life quality. The presence of well-defined, osteolytic lesions in the bone calls for an MRI or CT scan. Both can aid in accurately determining the entity. Additionally, management involves curettage and graft of the symptomatic and progressive lesions. Follow-up is mandatory.

\section{Conflicts of Interest}

The Authors declare that there are no conflicts of interest in relation to this study.

\section{Authors' Contributions}

D. Dammerer: Study design, literature research, data analysis, editing and writing of the article. J. Neugebauer: Data analysis, co- editing, writing and proofreading of the article. D. Putzer: Performed the literature research, data analysis and proofreading of the article. B. Henninger: Supervised the study results and proofread the article and performed the literature research. All Authors made pertinent contributions to the article, and proofread and approved the final article before submission.

\section{References}

1 Rehani B and Wissman R: Multiple intraosseous lipomatosis: a case report. Cases J 2: 7399, 2009. PMID: 19829952. DOI: 10.1186/1757-1626-2-7399

2 Uhl M, Herget GW and Rottenburger C: Radiologische Diagnostik von Knochentumoren. 2nd Edition. Thieme, 2015.

3 Döhler R and Harms D: Intraossäre Lipome. Z Orthop Ihre Grenzgeb 119: 138-141, 2008. DOI: 10.1055/s-2008-1051435

4 Milgram JW: Malignant transformation in bone lipomas. Skeletal Radiol 19: 347-352, 1990. PMID: 2165632. DOI: 10.1007/BF00193088

5 Milgram JW: Intraosseous lipomas: radiologic and pathologic manifestations. Radiology 167: 155-160, 1988. PMID: 3347718. DOI: 10.1148/radiology.167.1.3347718

6 Chung CB, Murphey M, Cho G, Schweitzer M, Hodler J, Haghihi P and Resnick D: Osseous lesions of the pelvis and long tubular bones containing both fat and fluid-like signal intensity: an analysis of 28 patients. Eur J Radiol 53: 103-109, 2005. PMID: 15607860. DOI: 10.1016/j.ejrad.2004.02.008

7 Campbell RSD, Grainger AJ, Mangham DC, Beggs I, Teh J and Davies AM: Intraosseous lipoma: report of 35 new cases and a review of the literature. Skeletal Radiol 32: 209-222, 2003. PMID: 12652336. DOI: 10.1007/s00256-002-0616-7

8 Reig-Boix V, Guinot-Tormo J, Risent-Martinez F, AparisiRodriguez F and Ferrer-Jimenez R: Computed tomography of intraosseous lipoma of os calcis. Clin Orthop Relat Res 221: 286-291, 1987. PMID: 3608313.

9 Muramatsu K, Tominaga Y, Hashimoto $\mathrm{T}$ and Taguchi T: Symptomatic intraosseous lipoma in the calcaneus. Anticancer Res 34: 963-966, 2014. PMID: 24511040.

10 Freiberg R, Air G, Glueck C, Ishikawa T and Abrams N: Multiple Intraosseous Lipomas with Type-IV Hyperlipoproteinemia: A case report. J Bone Joint Surg 56: 1729-1732, 1974. PMID: 4373109.

11 Whyte MP, Eddy MC, Podgornik MN and Mcalister WH: Polycystic bone disease: a new, autosomal dominant disorder. J Bone Miner Res 14: 1261-1271, 1999. PMID: 10457258. DOI: 10.1359/jbmr.1999.14.8.1261

12 Atay EF, Güven M, Çakar M, Başsorgun CI, Akman B and Bes C: An unusual cause of a cystic lesion with an osteochondral defect in the talusintraosseous lipoma. J Am Podiatr Med Assoc 101: 269-274, 2011. PMID: 21622640. DOI: $10.7547 /$ 1010269

13 Schatz SG, Dipaola JD, D'Agostino A, Hanna R and Quinn SF: Intraosseous lipoma of the calcaneus. J Foot Surg 31: 381-384, 1992. PMID: 1401740.

14 Greenspan A, Raiszadeh K, Riley GM and Matthews D: Intraosseous lipoma of the calcaneus. Foot Ankle Int 18: 53-56, 1997. PMID: 9013117. DOI: 10.1177/107110079701800112

15 Goto T, Kojima T, Iijima T, Yokokura S, Motoi T, Kawano H, Yamamoto A and Matsuda K: Intraosseous lipoma: a clinical study of 12 patients. J Orthop Sci 7: 274-280, 2002. PMID: 11956992. DOI: $10.1007 / \mathrm{s} 007760200046$ 
16 Palczewski P, Świątkowski J, Gołębiowski M and BłasińskaPrzerwa K: Intraosseous lipomas: A report of six cases and a review of literature. Pol J Radiol 76: 52-59, 2011. PMID: 22802856.

17 Szendroi $M$, Karlinger $\mathrm{K}$ and Gonda $\mathrm{A}$ : Intraosseous lipomatosis. A case report. J Bone Joint Surg Br 73: 109-112, 1991. PMID: 1991740. DOI: 10.1302/0301-620X.73B1.1991740

18 Murphey MD, Carroll JF, Flemming DJ, Pope TL, Gannon FH and Kransdorf MJ: From the Archives of the AFIP. RadioGraphics 24: 1433-1466, 2004. PMID: 15256634. DOI: $10.1148 /$ rg. 245045120
19 Kang HS, Kim T, Oh S, Park S and Chung SH: Intraosseous Lipoma: 18 Years of Experience at a Single Institution. Clin Orthop Surg 10: 234-239, 2018. PMID: 29854348. DOI: $10.4055 /$ cios 2018.10 .2 .234

Received December 23, 2020

Revised January 21, 2021

Accepted January 26, 2021 